\title{
Glycosuria in glomerular diseases: histopathology and clinical correlations
}

V. Woronik, I.F. Freitas, L.B. Saldanha, E. Sabbaga and M. Marcondes
Departamento de Nefrologia, Hospital das Clínicas, Faculdade de Medicina, Universidade de São Paulo, São Paulo, SP, Brasil
Correspondence

V. Woronik

Laboratório de Fisiopatologia

Renal

Av. Dr. Arnaldo, 455

3 o andar, Sala 3342

01246-903 São Paulo, SP

Brasil

Fax: 55 (011) 883-1693

Publication supported by FAPESP.

Received January 21, 1997

Accepted February 6, 1998

\section{Abstract}

There are doubts about the presence of glycosuria and the progress of glomerular disease. Some reports suggest that glycosuria could be an index of a more severe tubulointerstitial lesion. We investigated the presence of glycosuria in 60 patients with primary glomerular diseases: 17 patients $(28 \%)$ had glycosuria and 43 patients $(72 \%)$ were glycosuria free. The two groups were similar in age, arterial pressure and sex. Serum creatinine was higher in patients with glycosuria $(2.0$ $\pm 1.7 \mathrm{vs} 1.3 \pm 0.9 \mathrm{mg} / \mathrm{dl}, \mathrm{P}<0.05)$. The protein excretion rate was $7.5 \pm$ $3.7 \mathrm{vs} 5.3 \pm 4.2 \mathrm{~g} / \mathrm{day}(\mathrm{P}>0.05)$ in patients with and without glycosuria, respectively, while serum albumin was lower in patients with glycosuria $(1.7 \pm 0.6$ vs $2.7 \pm 1.0 \mathrm{~g} / \mathrm{dl}, \mathrm{P}<0.05)$. Several histological forms were present in the group with glycosuria, with membranous glomerulonephritis being the most frequent. Histological evidence of tubular atrophy and interstitial fibrosis prevailed in patients with glycosuria, suggesting a poor prognosis for these patients. We may conclude that the presence of glycosuria in patients with glomerular disease is associated with more pronounced tubular atrophy and interstitial fibrosis and therefore imply a poorer prognosis.

\section{Introduction}

Tubular dysfunction is not uncommon in glomerular diseases and is frequently detected by the appearance of glycosuria. Praga et al. (1) found 10 patients with glycosuria among 36 patients with nephrotic syndrome. Most of the patients reported in the literature were children with focal glomerulosclerosis, but some recent reports in adults point to membranous glomerulonephritis as the prevailing glomerular disease when there is glycosuria (1).

There are doubts about the progress of these glomerular diseases: some reports sug- gest that glycosuria could be an index of a more severe tubulointerstitial aggression and progression to chronic renal failure. In the present investigation we studied some aspects of tubulointerstitial lesion and glycosuria and correlated the lesion with glycosuria.

\section{Patients and Methods}

Sixty patients with a diagnosis of glomerulonephritis made by histological examination of kidney biopsies were studied in retrospect. The clinical and laboratory evaluation was made on the occasion of the kidney 
biopsy, and at that time no patient was under specific treatment for glomerular disease, or had been taking corticosteroids for at least six months. The patients were under symptomatic medication only if necessary, with furosemide and usual antihypertensive drugs. All the patients had normal fasting blood glucose levels.

The histological study was made by a renal pathologist who was not aware of the clinical diagnosis of the patients. Tubulointerstitial indexes (tubular atrophy and interstitial fibrosis) were classified on a scale from zero to four as follows: no lesion (zero), minimal (one), slight (two), moderate (three) and severe (four). Patients were allocated to two groups, with and without glycosuria, by the analysis of at least two urine specimens at two different times, at least three months apart. We defined glycosuria as the presence of any glucose in the urine by the method

Table 1 - Clinical characteristics of the patients with (G1) and without (G2) glycosuria.

Data are reported as mean $\pm \mathrm{SD} .{ }^{*} \mathrm{P}<0.05, \mathrm{G} 1 \mathrm{vs} \mathrm{G} 2$ (Student $t$-test)

\begin{tabular}{lcc}
\hline & $\mathrm{G} 1$ & $\mathrm{G} 2$ \\
\hline $\mathrm{N}$ & $17(28 \%)$ & $43(72 \%)$ \\
Sex & $12 \mathrm{M}: 5 \mathrm{~F}$ & $27 \mathrm{M}: 16 \mathrm{~F}$ \\
Age (years) & $28.9 \pm 11.0$ & $31.9 \pm 15.2$ \\
Systolic arterial pressure (mmHg) & $134 \pm 18$ & $126 \pm 16$ \\
Diastolic arterial pressure (mmHg) & $86 \pm 11$ & $83 \pm 11$ \\
Serum creatinine (mg/dl) & $2.0 \pm 1.7$ & $1.3 \pm 0.9^{*}$ \\
Serum albumin (g/dl) & $1.7 \pm 0.6$ & $2.7 \pm 1.0^{*}$ \\
Urinary protein excretion (g/24 h) & $7.5 \pm 3.7$ & $5.3 \pm 4.2$
\end{tabular}

Table 2 - Histological diagnosis of patients with (G1) and without (G2) glycosuria.

\begin{tabular}{lcr}
\hline & G1 & G2 \\
\hline Membranous glomerulonephritis & 6 & 6 \\
Focal glomerulosclerosis & 5 & 18 \\
Membranoproliferative glomerulonephritis & 3 & 3 \\
Minimal change nephropathy & 2 & 5 \\
Mesangial proliferative glomerulonephritis & 0 & 4 \\
Mesangial lgA glomerulonephritis & 1 & 7
\end{tabular}

described below.

Serum creatinine was determined by Jaffé's method using autoanalyser equipment, glycosuria by the GOD-PAP colorimetric and enzymatic method, urinary protein by Ponceau's method and serum albumin by protein electrophoresis on agar cellulose gel.

Statistical analysis was performed by the Student t-test and the Wilcoxon rank sum test with the level of significance set at $\mathrm{P}<0.05$. Data are reported as mean $\pm \mathrm{SD}$.

\section{Results}

Seventeen patients (28\%) had glycosuria while 43 patients $(72 \%)$ did not (Table 1$)$. Mean glycosuria was $1.71 \mathrm{~g} / 1$ with a range of 0.3 to $5.5 \mathrm{~g} / 1$ and there was no correlation between glycosuria and any other parameters of renal function, not even protein excretion rate. The two groups did not differ in mean age, which was $28.9 \pm 11.0$ and $31.9 \pm$ 15.2 years, respectively (Table 1 ). Males were predominant in the group with glycosuria (12 males, 5 females) and also in the group without glycosuria, whose distribution was 27 males and 16 females (Table 1), but the difference was not statistically significant.

The mean systolic and diastolic arterial pressures did not differ between groups (Table 1) but the groups differed in serum creatinine, which was $2.0 \pm 1.7$ vs $1.3 \pm 0.9$ $\mathrm{mg} / \mathrm{dl}(\mathrm{P}<0.05)$ for patients with and without glycosuria, respectively (Table 1 ), and in serum albumin, which was $1.7 \pm 0.6$ vs $2.7 \pm$ $1.0 \mathrm{~g} / \mathrm{dl}$, respectively $(\mathrm{P}<0.05)$ (Table 1). The protein excretion rate appeared to differ between groups $(7.5 \pm 3.7 \mathrm{vs} 5.3 \pm 4.2 \mathrm{~g} /$ day, respectively), but the difference did not reach statistical significance (Table 1).

All patients were submitted to kidney biopsy and the histological diagnoses are shown in Table 2. The histological picture of tubulointerstitial damage was studied in 10 patients with and 10 patients without glyco- 
suria by a pathologist who was not aware of the clinical diagnoses of the patients. The results are shown in Table 3.

\section{Discussion}

Tubular dysfunction, frequently expressed by glycosuria, may be present in about $30 \%$ of patients with nephrotic syndrome and is more commonly reported in children with focal glomerulosclerosis.

There are doubts about its meaning as an indicator of the progress of glomerular disease, with some reports suggesting that the appearance of glycosuria is a sign of poor prognosis, with the establishment of renal failure in this group earlier than that without glycosuria (1-3). Several causes have been proposed to justify tubular dysfunction with glycosuria in these patients. Praga et al. (1) suggested a possible role of renal vein thrombosis in these patients but rejected this possibility because the patients showed no clinical-laboratory signs of the disorder.

Some other reports have linked the finding of anti-tubular membrane antibody sometimes present in those glomerular diseases to the functional abnormality (4). However, the analysis of kidney biopsy specimens does not support this hypothesis because there are only a few patients with glycosuria presenting immunoglobulin deposits on the tubular membrane (5).

Other reports have indicated the possibility of a direct damage caused by the high protein levels present in the tubular fluid of these patients. This situation imposes a high workload on tubular cells for the reabsorption of protein, with the consequent production of excess reactive oxygen species that impair normal cell function such as glucose reabsorption (6-8). This argument is based on the finding of a higher protein excretion rate in patients with glycosuria (1).

Furthermore, tubular lesion proteinuria could cause important interstitial inflammation and fibrosis by still unelucidated mecha- nisms (9-12).

Eddy (10) developed a model of "protein-overload proteinuria" by injecting bovine albumin into rats. High proteinuria was accompanied by an interstitial cell infiltrate. The author speculated that the increased trafficking and degradation of albumin in these cells may lead to the release of degradative enzymes into the interstitium.

Taking a different approach, Schreiner et al. (13-15) found that the urine of proteinuric rats and humans contains a still unidentified but specific macrophage lipid chemotactic factor released by proximal tubules after the metabolism of albumin-bound fatty acids during states of heavy protein loss.

On the other hand, several authors have suggested that increased ammoniagenesis by tubular cells subjected to heavy proteinuria may be noxious to the interstitium. Thus, the ammonia generated is thought to activate the third component of complement which then leads to the activation of the complement cascade $(16,17)$. This in turn could lead to the influx of inflammatory cells, the elaboration of inflammatory mediators and increased collagen synthesis $(18,19) . \mathrm{C}_{3}$ could also be synthesized locally by tubular cells and its

Table 3 - Tubular atrophy and interstitial fibrosis in kidney biopsies from patients with glycosuria $(\mathrm{G} 1 ; \mathrm{N}=10)$ and without glycosuria $(\mathrm{G} 2 ; \mathrm{N}=10)$.

Tubular atrophy: $P<0.01$, G1 vs $G 2$ (Wilcoxon rank sum test). Interstitial fibrosis: $P<0.05, \mathrm{G} 1$ vs $\mathrm{G} 2$ (Wilcoxon rank sum test)

G1

Tubular atrophy

No lesion

Minimal

Slight

Moderate

Severe

1
2
4
3
0

Interstitial fibrosis

No lesion

Minimal

Slight

Moderate

Severe

$\begin{array}{ll}5 & 9 \\ 1 & 1 \\ 3 & 0 \\ 1 & 0 \\ 0 & 0\end{array}$


production upregulated by interleukin 2 secreted locally by $\mathrm{T}$ cells (20), thus further fueling the process.

The hypothesis stated above, though not definitive, tries to explain the mechanisms of tubulointerstitial dysfunction secondary to protein overflow in the tubules (21).

Our data permit the following comments. Glycosuria was present in $28 \%$ of our patients with glomerular disease, as also reported for other series. The groups with and without glycosuria did not differ in age, arterial pressure or sex distribution. The protein excretion rate did not differ between groups although serum albumin was lower in the group with glycosuria, suggesting that this group had a higher protein excretion sometime before the beginning of the study.

Histological studies in the literature suggest the association of glycosuria with focal glomerulosclerosis, particularly in children $(2,3)$. In our adult population we found various histological lesions in glycosuric patients and membranous glomerulonephritis was the most common form, in agreement with previously reported data (1). Other histological forms were focal glomerulosclerosis ( 5 cases), membranoproliferative glomerulonephritis (3 cases), mesangial IgA glomerulonephritis ( 1 case), and minimal change nephropathy ( 2 cases).

In some patients the evolution of glycosuria was dependent on protein excretion. Thus, upon remission of the glomerular disease as was the case for patients with minimal change ( 2 cases), glycosuria disappeared. In some cases such as focal glomerulosclerosis or membranous glomerulonephritis, glycosuria also decreased with partial remis- sion of the disease, indicating a functional cause for the disorder.

When studying the tubulointerstitial lesion we found more tubular atrophy and interstitial fibrosis in the cases with glycosuria. This suggests a relationship between the causes that lead to glycosuria and those linked to the histological lesions, although these causes have not been determined.

Our data agree with reports by others indicating that glycosuria is not a characteristic of some particular glomerular lesion but may be found in various histological forms.

The group with glycosuria showed worse renal function and lower serum albumin levels and seemed to have a higher protein excretion rate. The group also showed more intense changes in tubular atrophy and interstitial fibrosis than the group without glycosuria, confirming serious functional and histological changes. However, as in some patients with minimal glomerular lesions in which proteinuria as well as glycosuria disappear with the remission of the disease, we may say that in some cases there may be only functional disability of the tubular cells secondary to proteinuria.

Thus, we propose that the finding of glycosuria in glomerular diseases with proteinuria may be related to some functional impairment of tubular cells and may indicate more intense tubulointerstitial changes and a poor prognosis in glomerular diseases.

In conclusion, our results show that the presence of glycosuria is not uncommon in glomerular diseases and that its appearance is related to a worse index of tubulointerstitial lesion and may therefore imply a poorer prognosis. 


\section{References}

1. Praga $M$, Andres $A$, Hernandez $E$, Montoyo C, Mazuecos A, Campo C, Morales JM \& Rodicio JL (1991). Tubular dysfunction in nephrotic syndrome: incidence and prognostic implications. Nephrology, Dialysis, Transplantation, 6: 683-688.

2. McVicar M, Exeni R \& Susin M (1980). Nephrotic syndrome and multiple tubular defects in children: an early sign of focal segmental glomerulosclerosis. Journal of Pediatrics, 97: 918-922.

3. Bouissou F, Barthe $\mathrm{Ph} \&$ Pierragi MT (1980). Severe idiopathic nephrotic syndrome with tubular dysfunction (report of nine pediatric cases). Clinical Nephrology, 14: 135-141

4. Bergstein J \& Litman N (1975). Interstitial nephritis with anti-tubular basement membrane antibody. New England Journal of Medicine, 292: 875-878.

5. Petterson E, Tormroth $T$ \& Miettinen A (1984). Simultaneous antiglomerular basement membrane and membranous glomerulonephritis: case report and literature review. Clinical Immunology and Immunopathology, 31: 171-180.

6. Schrier RW, Harris DCH, Chan L, Shapiro JI \& Caramelo C (1988). Tubular hypermetabolism as a factor in the progression of chronic renal failure. American Journal of Kidney Diseases, 12: 243-249.

7. Harris DCH, Chan L \& Schrier RW (1988). Remnant kidney hypermetabolism and progression of chronic renal failure. American Journal of Physiology, 254: F267-F276.

8. Rovin BH, Wurst E \& Kohan DE (1990).
Production of reactive oxygen species by tubular epithelial cells in culture. Kidney International, 37: 1509-1514.

9. Eddy AA \& Michael AF (1988). Acute tubulointerstitial nephritis associated with aminonucleoside nephrosis. Kidney International, 33: 14-23.

10. Eddy AA (1989). Interstitial nephritis induced by protein-overload proteinuria. American Journal of Pathology, 135: 719733.

11. Ong ACM \& Fine LG (1994). Loss of glomerular function and tubulointerstitial fibrosis: cause or effect? Kidney International, 45: 345-351.

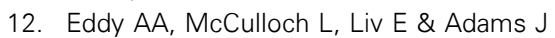
(1991). A relationship between proteinuria and acute tubulointerstitial disease in rats with experimental nephrotic syndrome. American Journal of Pathology, 138: 1111-1123.

13. Schreiner GF, Kees-Folts D \& Delmez J (1992). Characterization of a macrophagespecific lipid chemotactic factor in the urine and peritoneal dialysate of nephrotic patients with declining renal function. Journal of the American Society of Nephrology, 3: 419 (Abstract).

14. Thomas ME \& Schreiner GF (1993). Contribution of proteinuria to progressive renal injury: consequences of tubular uptake of fatty acid bearing albumin. American Journal of Nephrology, 13: 385-398.

15. Kees-Folts D, Sadow JL \& Schreiner GF (1994). Tubular catabolism of albumin is associated with the release of an inflammatory lipid. Kidney International, 45:
1697-1709.

16. Nath KA, Hostetter MK \& Hostetter TH (1985). Pathophysiology of chronic tubulointerstitial disease in rats: interactions of dietary acid load, ammonia and complement component $C_{3}$. Journal of Clinical Investigation, 76: 667-675

17. Rustow R, Jackson MJ, Critchley $M$ \& Bone JM (1992). Tubular metabolism of aproonin 99 Tc and urinary ammonia: effect of proteinuria. Mineral and Electrolyte Metabolism, 18: 108-112.

18. Hänsch GM, Schönermark M, Wagner $C$, Schieren G \& Jahn G (1991). The terminal complement complex C5b-9: A possible mediator of acute and chronic glomerulonephritis. In: Hatano M (Editor), Proceedings of the XIth International Congress of Nephrology. Vol. II. Springer-Verlag, New York, 888-897.

19. Torbohm I, Schönermark $M$, Wingen $A M$ Berger B, Rother K \& Hänsch GM (1990). C5b-8 modulates the collagen release of human glomerular epithelial cells. Kidney International, 37: 1098-1104.

20. Broolmans RA, Stegmann APA, van Dorp WT, van der ark AAJ, van der Wonnde FJ, van Es LA \& Daha MR (1991). Interleukin 2 mediates stimulation of complement $\mathrm{C}_{3}$ biosynthesis in human proximal tubular epithelial cells. Journal of Clinical Investigation, 88: 379-384.

21. Williams JD \& Coles GA (1994). Proteinuria - a direct cause of renal morbidity? Kidney International, 45: 443-450. 